\title{
Casos para Ensino:
}

\section{Uma Gota no Oceano e Vários Desafios para a Ocean Drop}

\author{
A Drop in the Ocean and Several Challenges for the Ocean Drop
}

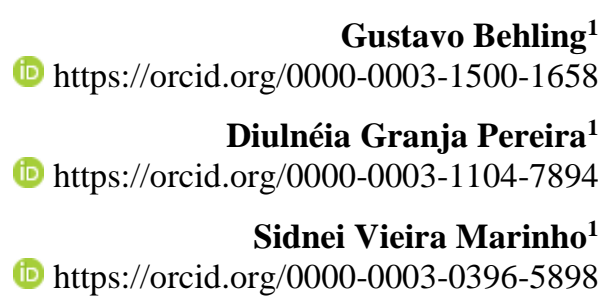

Universidade do Vale do Itajaí, Programa de Pós-Graduação em Administração, Biguaçu, SC, Brasil ${ }^{1}$

Artigo recebido em 27.02.2018. Última versão recebida em 31.07.2018. Aprovado em 18.11.2018. Editora Associada: Profa. Anete Alberton 


\section{Introdução}

Final de tarde de verão e mais um expediente intenso se encerra para os quatro ex-colegas da faculdade de Oceanografia, atualmente sócios. Um final de dia daqueles, onde a melhor opção é espairecer e um bom mergulho surgiu como uma boa ideia para os jovens naquele momento. Há menos de uma hora, eles haviam realizado uma reunião para avaliar os resultados do último ano, que trouxe consigo uma reformulação total no modelo de negócio da Brastax, empresa que teve sua proposta de valor refutada pelo mercado, originando a Ocean Drop, primeira empresa brasileira especializada em nutrição com microalgas, localizada na cidade de Balneário Camboriú, Santa Catarina.

Os resultados obtidos trouxeram aos sócios muita satisfação, mas as dúvidas e os desafios que vinham pela frente eram árduos. Um ano após o evento de lançamento dos produtos, ocorrido em fevereiro de 2016, a empresa havia conquistado uma importante parcela do mercado e resultados de vendas muito acima do esperado. Contudo, decisões importantes ainda precisavam ser tomadas.

O oceano, que representava toda a fonte de inspiração da Ocean Drop, não foi suficiente para acalmar os pensamentos sobre as decisões proteladas na reunião, e os questionamentos persistiam. Como promover a escalabilidade da Ocean Drop, sem reduzir a sua rentabilidade? E a Brastax, sonho que motivou este grupo de jovens. É possível torná-la um negócio viável? Um novo encontro foi agendado em duas semanas para que os sócios tivessem tempo para refletir e maturar as suas decisões.

\section{Algo com Algas}

Diferentemente da maioria dos estudantes de oceanografia, que após o curso optam por permanecer na área acadêmica, trabalhar com consultoria ou como funcionários de grandes empresas, Leandro e Marcelo tinham o sonho de empreender. O ano era 2012, e os amigos sabiam que seu futuro profissional seria aplicar o conhecimento científico obtido no curso para criar uma nova empresa. Antes mesmo de terem uma ideia de que tipo de empresa criar, resolveram formar um time. Convidaram outros dois colegas da faculdade que cursavam em Itajaí (SC), Janaína, que se destacava na disciplina de química, fundamental para a área e André, tido como o nerd da turma e que poderia contribuir muito com seu vasto conhecimento. Havia muita sinergia entre os membros e a equipe estava formada.

Mas que tipo de empresa abrir? Para atuar em que setor? A oceanografia é muito abrangente, envolvendo áreas como química, física, biologia e geologia. De todas essas ciências, um leque enorme de oportunidades de negócio diferentes pode surgir. A discussão chegou a um consenso: o novo negócio deveria envolver microalgas. Dois motivos levaram a essa decisão: um dos membros do grupo, Leandro, tinha uma experiência bastante significativa com microalgas, adquirida nos três anos de ensino médio, quando participou de um programa de iniciação científica. Neste período, Leandro desenvolveu pesquisas e participou de diversos eventos científicos da área. Outra razão para optar pelas microalgas foram as diversas oportunidades de negócio apresentadas pelos professores em duas disciplinas do curso de oceanografia (ficologia e planctologia). Nessas aulas, os professores provocavam os estudantes para o potencial de exploração das microalgas que poderiam servir, dentre outras coisas para produzir biodiesel, fármacos, pigmentos, tratamento de efluentes e alimentação humana e animal.

Durante esse período de maturação da ideia, surgiu um grande incentivo para a equipe: o Prêmio Santander de Empreendedorismo 2012. O prêmio é destinado a alunos de graduação e pós-graduação e tem por objetivo apoiar e reconhecer a criação e o desenvolvimento de projetos de estudantes com perfil e postura empreendedora (Santander, 2015). Como os futuros sócios ainda estavam cursando a graduação, ficou decidido que os colegas participariam do prêmio, submetendo um plano de negócio. No entanto, haviam pelo menos, dois grandes problemas pela frente: trabalhar com algas, mas de que forma, especificamente? E, como um grupo de oceanógrafos desenvolveria um plano de negócio capaz de vencer um concurso, sem o conhecimento técnico necessário para isso? 
Após muitas deliberações a primeira dúvida foi sanada e a equipe encontrou uma ideia de negócio: tratar os efluentes de abatedouros de frango utilizando microalgas para garantir o saneamento da água e reutilizá-la no processo industrial em fins não nobres. Os estudantes pesquisaram a respeito e descobriram que para cada ave abatida são utilizados 20 litros de água no processo produtivo. Toda essa água vira esgoto, repleto de matéria orgânica, que precisa de tratamento antes de ser devolvida à natureza. As algas têm uma enorme capacidade de tratar esses efluentes, visto que a matéria orgânica é seu alimento. Ao final desse processo, a água tratada retornaria para o processo produtivo e haveria ainda uma grande quantidade de algas, com alto poder nutritivo que poderiam ser utilizadas na alimentação dos frangos, fechando um ciclo totalmente sustentável.

Para os membros da equipe, estava claro o potencial dessa oportunidade. O fato de Santa Catarina ser o segundo maior produtor de frangos do Brasil, abatendo mais de 800 mil aves por ano, conforme dados da Federação das Indústrias do Estado de Santa Catarina (FIESC, 2015) e o Paraná, líder nacional ser um estado vizinho, embasavam essa convicção. Além disso, à época o país vivia uma enorme crise de escassez da água e a eficiência no uso passou a ser uma preocupação de todos, principalmente das empresas que utilizam água em seus processos produtivos.

Resolvida a primeira dúvida, a empresa já tinha até nome: Brastax. Faltava escrever o plano de negócio. O próprio regulamento do prêmio previa um modelo de plano de negócio, que deveria ser organizado nos seguintes tópicos: Capa, Índice, Sumário Executivo, Plano de produto/serviço, Plano de marketing, Plano de gestão e organização, Plano financeiro e Apêndice, todos resumidos em um limite de vinte páginas (Santander, 2012). Era de fato, muita informação nova para quem nunca havia tido contato com a gestão. Foi uma grande barreira, superada com muito esforço pela equipe.

“Agora que já sabíamos o conteúdo necessário para elaboração de um plano de negócio, era a hora de botar a mão na massa! Fomos para a internet pesquisar quais informações um bom plano deveria conter. Pesquisamos alguns planos de negócio prontos e levantamos o que tinham de pontos positivos que poderiam nos servir de inspiração." (Leandro).

As tarefas foram divididas, mas tudo era conversado e acordado por todos. Nesse trabalho colaborativo, os jovens incentivavam uns aos outros.

"Tínhamos uma ideia muito clara, uma tecnologia a propor que poderia contribuir para resolver um problema ambiental grave. Mas, precisávamos fazer um estudo de mercado, que nos desse a dimensão do potencial deste negócio" (Leandro).

E de fato os resultados do estudo de mercado foram bastante animadores, denotando que a produção de aves é um mercado enorme no Brasil. Por ser um setor econômico importante e bastante estruturado, não foi difícil encontrar informações já publicadas que municiassem a elaboração do plano de negócio. Os relatórios anuais da União Brasileira de Avicultura (UBABEF, 2012), por exemplo, mostravam que no ano anterior, a produção de carne de frango no país havia atingindo os 13,058 milhões de toneladas, volume que havia dobrado nos últimos dez anos. A região Sul, onde os jovens moravam era responsável por $61,53 \%$ desta produção (UBABEF, 2012). Esses números animavam os membros da equipe e demonstravam que a ideia tinha muito potencial.

"A maior dificuldade enfrentada nesta fase, foi a elaboração das projeções financeiras. Jamais havíamos feito algo próximo disto, de planejar um negócio do ponto de vista financeiro. Para dimensionar os investimentos necessários em tecnologia, foram necessários diversos orçamentos, também foi muito trabalhoso levantar os custos de mão-de-obra e principalmente definir a forma de gerar receita do negócio" (Leandro).

Mas no final, todos ficaram extremamente satisfeitos com o plano de negócio elaborado. A equipe conseguiu expor a sua proposta de maneira embasada, caracterizando muito bem o problema e o impacto gerado ao meio ambiente. Os números do mercado e a proposta técnica extremamente inovadora, também chamavam a atenção. Assim, o plano de negócio submetido ao prêmio foi sendo classificado fase a fase e ficou entre os cinco finalistas. Era o momento de apresentar em São Paulo, um pitch, (apresentação de uma ideia de negócio e sua proposta de valor), o sonho começava a ganhar forma e Leandro pensava alto: "precisamos captar investidores". 
Além de conquistar o primeiro lugar, a equipe foi recompensada com 50 mil reais. Aquele era um momento importante para a empresa, que sequer havia nascido ainda. Dividir o prêmio entre os quatro membros da equipe ou investir tudo na empresa? A segunda opção foi unânime.

\section{O período de incubação}

Com a conquista do Prêmio Santander de Empreendedorismo, os estudantes foram convidados a participar da incubadora tecnológica da universidade onde estudavam, com o objetivo de implementar o plano de negócio, criando uma empresa. O desafio foi aceito e a empresa iniciou o seu período de incubação. Nesta fase, a empresa passou a funcionar dentro da universidade, utilizando sua estrutura e recebendo apoio para o desenvolvimento de pesquisas aprofundadas de mercado, planejamento de um protótipo e criação do modelo de negócio.

Paralelamente a isso, cada um dos integrantes, já chegando ao final da faculdade de oceanografia direcionou seu trabalho de conclusão de curso para desenvolver uma das partes do processo: como produzir a alga, como tratar os resíduos do processo produtivo, e de que forma nutrir os frangos com as microalgas. Muito estudo foi necessário para desenvolver a tecnologia.

\footnotetext{
"Até essa fase ainda não tínhamos tido nenhuma interação com o mercado. O que tínhamos era uma ideia, que todos avaliavam como muito boa. Buscamos nesse momento o contato com o setor de inovação de um grande abatedouro no Paraná para apresentar a ideia e receber um feedback. O retorno foi muito positivo e a empresa nos concedeu uma carta de recomendação, informando que a ideia fazia muito sentido e que era válido se aprofundar no desenvolvimento da tecnologia. Outra conquista foi uma carta de recomendação da União Brasileira de Avicultura, órgão máximo do setor, respaldando a ideia" - recorda Leandro.
}

A aceitação da ideia por parte da mídia também foi imediata. A empresa começou a figurar em diversos veículos de repercussão nacional, como o Pequenas Empresas \& Grandes Negócios e a participar de prêmios na área de sustentabilidade e de captação de recursos.

Como ganhadora do prêmio nacional de empreendedorismo universitário, a Brastax foi convidada a participar de mais um concurso, que reuniria os campeões do mesmo prêmio nos países integrantes da SEGIB - Secretaria Geral Ibero-Americana. A apresentação realizada no Panamá também conquistou o $1^{\circ}$ lugar e mais uma recompensa de 20 mil euros, todos investidos na empresa. Outro aporte importante foi conseguido mediante aprovação em edital do SENAI - Serviço Nacional de Aprendizagem Industrial, para projetos inovadores, na qual a empresa recebeu um aporte de 500 mil reais para desenvolvimento da tecnologia necessária.

\section{Pivota, pivota e. pivota}

Com a tecnologia em desenvolvimento os empreendedores foram ao mercado avaliar a aceitabilidade da oportunidade de negócio. Esse processo ocorreu durante os anos de 2013 e 2014. Contra todos os prognósticos, o resultado foi decepcionante. Os empresários ouviam a ideia, diziam ser extremamente interessante, mas que não estavam dispostos a fazer o investimento necessário para aplica-la em seu processo produtivo. $\mathrm{O}$ grupo percebeu que as indústrias davam pouca atenção ao problema do tratamento de efluentes, que era visto unicamente como uma despesa obrigatória. Seria necessária uma mudança de cultura e, na visão dos sócios da Brastax, a falta de um especialista na área para argumentar de maneira mais eficiente com os clientes, pesou para a pouca aceitação da ideia.

Outro problema, foi a falta de um MVP Minimum Viable Product (produto mínimo viável). O MVP é uma solução (produto/serviço) que um segmento de clientes dá valor, ou seja, algo pelo qual estariam dispostos a pagar, utilizando a menor quantidade de recursos e e o menor tempo possível para desenvolvimento. Nesse sentido, haviam dúvidas sobre como a Brastax geraria receita: uma alternativa seria a empresa construir toda a tecnologia e vender a biomassa de alga para seus clientes. Ou os clientes pagariam pela tecnologia e a Brastax operaria o sistema. Porém, os sócios não tinham clareza quanto a forma de operar. Além disso, não havia comprovação dos resultados da nova tecnologia, e se, de fato, proporcionaria os resultados prometidos, visto que a Brastax não teve a oportunidade de testar o processo 
em um abatedouro. As primeiras decepções no mercado fizeram os sócios repensar o modelo de negócios e Leandro mais uma vez pensava alto:

\begin{abstract}
"Precisamos pivotar. Visando reduzir o investimento necessário, não seria viável utilizar uma alga de produção mais rápida e barata no processo? Talvez fosse mais viável mercadologicamente, apenas tratar os efluentes sem utilizar as algas na alimentação das aves. E se o mercado fosse aberto para outros tipos de produtores, como porco, peixe, ração animal, visto que as algas serviriam para tratar qualquer resíduo orgânico?"
\end{abstract}

Porém, todas essas hipóteses levantadas foram testadas no mercado e se mostraram ineficientes. Apesar do esforço de rodar praticamente todo o estado visitando possíveis clientes, todas as conversas que se iniciavam, de forma tímida depois de muita insistência, esbarravam no fato de que, os possíveis clientes viam sentido na proposta, mas não estavam interessados em investimentos que retornariam apenas no longo prazo.

Já haviam se passados dois anos da elaboração do plano de negócio inicial e, desde então, os sócios da empresa retiraram valores irrisórios como remuneração. $\mathrm{O}$ curso superior estava chegando ao fim e a pressão por fazer com que a ideia de negócio se tornasse viável aumentava. Os recursos estavam esgotando e algo urgente precisaria ser feito. Nesse momento, a empresa recebeu o aporte financeiro de dois investidores anjo. Dois estagiários da empresa, também estudantes universitários que acreditavam na ideia, investiram suas economias na empresa, proporcionando um respiro fundamental naquele momento.

\title{
Uma nova missão
}

O ano de 2015 foi o divisor de águas da Brastax. Com os recursos esgotados, decisões importantes precisavam ser tomadas. Foi então que surgiu a oportunidade da empresa participar do programa Darwin Starter de aceleração. Mais de 200 startups se inscreveram e a Brastax foi selecionada para um período de seis meses de aceleração, na qual a aceleradora investiria 150 mil reais em recursos financeiros e outros 350 mil reais em uma tool box, com diversas ferramentas de gestão. Além disso, a empresa seria acompanhada por um mentor e um padrinho e em contrapartida, a aceleradora receberia uma participação no capital social da Brastax.

Na primeira semana do processo de aceleração, a empresa "virou de ponta cabeça", como conta Leandro. Foi o momento de uma decisão estratégica importante: aplicar todo o recurso da aceleradora, insistindo em uma ideia que já havia sido testada e refutada pelo mercado? Ou pensar em algo diferente? Em uma conversa, Leandro argumentou com os sócios:

"Devemos nos direcionar para onde o dinheiro já esteja girando. Onde não seja preciso criar uma cultura."

Foi então que os sócios da empresa pensaram em direcionar a atuação para o mercado de nutrição humana com microalgas. Diversas pesquisas de mercado foram realizadas para compreender qual o tamanho desse mercado no país e se existia demanda. A resposta era positiva. Cogitaram então, a hipótese de tornar a Brastax uma produtora de alga, para comercialização no mercado interno e externo. Esse novo modelo exigiria a construção de uma fazenda e um investimento na ordem de 2 milhões de reais. Além disso, o tempo de regulamentação poderia ser de 2 a 3 anos. Os riscos eram muito grandes e a ideia acabou descartada.

Outra oportunidade surgiu: que tal comprar o produto acabado, aplicando um branding (estratégia de marca) diferenciado e tornando-se a primeira empresa brasileira especialista em nutrição com microalgas? Cada vez mais as pessoas têm uma maior quantidade de tarefas para realizar e, por vezes, isso acaba limitando a atenção dada a um aspecto fundamental para a saúde e qualidade de vida: a alimentação. Este cenário de complexidade para cuidar da saúde, especificamente tratando-se de alimentação, foi o grande motor e direcionador para a mudança de atividade da Brastax.

Dentre as empresas estabelecidas nesse tipo de mercado, que podem ser consideradas como possíveis concorrentes está a Mundo Verde, com 29 anos de atuação é considerada líder no conceito de vida saudável por meio da alimentação, possuindo inclusive franquias do segmento na América Latina. 
No entanto, a mesma comercializa mais de 8 mil itens e as algas compõem esse portfólio, não sendo o produto principal da empresa, que no Brasil está mais concentrada nos estados do Rio de Janeiro e São Paulo. Demais concorrentes, possuem estratégia de marketing muito fraca, com embalagens que mais se assemelham a medicamentos do que a alimentos.

O martelo estava batido. Foi definida então uma nova missão: simplificar a alimentação das pessoas com as microalgas. Microalgas são alimentos $100 \%$ naturais, altamente concentrados em nutrientes, vitaminas, antioxidantes e minerais, que com uma pequena quantia diária garantem uma carga nutricional adequada. As pesquisas realizadas demonstraram que dois produtos poderiam ser comercializados no Brasil, por questões de regulamentação: a Spirulina, que oferece nutrição prática, aumento de energia, foco e equilíbrio mental, cuidado com o coração e evita excessos na alimentação através da saciedade e a Chlorella que purifica o organismo, renova as células e tecidos do corpo, fortalece o sistema imunológico, regula o organismo e melhora a pele e os cabelos.

"Precisamos tirar a cara de remédio desses produtos, esses tubinhos brancos parecem remédio, mas o que vendemos é alimento" - alertou Leandro.

Iniciou-se então o desenvolvimento de um propósito da empresa, sua missão, visão e valores, muito diferentes das empresas estabelecidas no mercado. E um novo nome: a Ocean Drop, que passou a ser o braço de alimentação humana da Brastax.

\section{A Ocean Drop}

O processo de branding da Ocean Drop foi concebido para atingir três personas desenhadas com base em argumentos técnicos bem definidos. Esse processo de segmentação foi uma das ferramentas proporcionadas pela aceleração. Os três públicos da Ocean Drop são:

- Pessoas com rotina intensa, que buscam cuidar da alimentação e manterem-se energizadas e nutridas, mesmo diante de uma rotina intensa de atividades.

Vegetarianos e veganos que buscam nas microalgas a complementação de nutrientes essenciais para o corpo.

- Atletas profissionais que visam aumentar a sua performance e recuperar-se de maneira $100 \%$ natural.

O processo de desenvolvimento dos produtos e de comunicação é planejado para essas três personas específicas. Além disso, o DNA da empresa está voltado ao desenvolvimento de uma cultura de respeito e integração do homem ao meio ambiente. A Ocean Drop não pretende apenas atuar como empresa ecologicamente sustentável, mas também empoderar os seus consumidores a abraçar a causa da proteção natureza e, em especial, dos oceanos.

A marca e os produtos da Ocean Drop foram lançados oficialmente no dia 18 de fevereiro de 2016 no evento Meetup Startup SC e Demo Day Darwin Starter, realizado na ACATE - Associação Catarinense das empresas de Tecnologia de Florianópolis-SC e passaram a ser vendidos exclusivamente no canal e-commerce no site da empresa (https://www.oceandrop.com.br/) para consumidores finais B2C - Business to consumer (Negócios entre empresas e consumidores).

Os produtos da Ocean Drop (Spirulina e Chlorella) são ecologicamente corretos, suas embalagens recicláveis e com a menor utilização possível de plásticos. As embalagens possuem 240 cápsulas que duram dois meses (o consumo é de quatro cápsulas diárias). Embora o custo-benefício para o consumidor seja melhor do que o das marcas concorrentes, custo de compra é maior, já que existem concorrentes com embalagens de 15 cápsulas. Mas a Ocean Drop busca fugir da imagem milagrosa (e errônea) que alguns consumidores fazem das microalgas. $\mathrm{O}$ tempo de dois meses, segundo a assessoria recebida por nutricionistas, é necessário para o corpo se adaptar ao produto e o cliente perceber os resultados.

A matéria-prima é importada, encapsulada e embalada por um parceiro da empresa. Essa opção reduz a margem de lucro, já que a Ocean Drop atua apenas na ponta da cadeia. Porém, essa opção foi 
considerada a mais viável para reduzir o investimento e o tempo necessários para que a empresa pudesse produzir suas próprias algas.

Percebendo a oportunidade de gerar negócios no canal B2B - Business to business (Negócios entre empresas), a empresa definiu a estratégia de estar presente nas melhores lojas de produtos naturais do país. Para isso, ao invés do modelo tradicional de vendedor externo, optou pela adoção do insigth sales. Um pré-vendedor faz a qualificação das lojas, por meio de critérios como o posicionamento da marca, presença nas mídias sociais, disponibilidade em canais de comunicação com os consumidores, entre outros. Lojas que passam por esse filtro e tornam-se qualificadas, são contatadas pelo vendedor que oferece os produtos da empresa e treinamento online sobre os produtos. A aceitação tem sido boa e, embora a margem nesse canal seja muito inferior ao B2C, a maior parte das vendas acaba ocorrendo por meio de recompra, não necessitando um investimento significativo. Atender o canal B2B também é importante para a marca se fazer presente frente a seus concorrentes nas gôndolas das lojas.

\section{Os resultados das vendas}

Um ano após o evento de lançamento dos produtos, a Ocean Drop acumula números surpreendentes para uma startup. A empresa cresceu $40 \%$ ao mês no primeiro ano de atuação, saindo do zero para um faturamento de 600 mil reais. Mais de 3.200 consumidores adquiriram os produtos via canal B2C e os produtos estão disponíveis em cerca de 100 lojas de produtos naturais de todas as regiões do país. Atualmente, o volume de recompra, em relação as vendas totais da empresa, é de $15 \%$. Estatísticas do e-commerce, mostram que $20 \%$ de recompra é um índice excelente.

Os resultados, segundo o sócio da empresa, são fruto de um trabalho bem planejado no canal B2B e de investimentos pesados em publicidade no B2C. A empresa busca estar bem posicionada em qualquer termo de busca no Google relacionado à Spirulina e Chlorella. Além disso, utiliza as mídias sociais, principalmente o Facebook (https://www.facebook.com/myoceandrop) e o Instagram (https://www.instagram.com/oceandrop) para divulgar informações sobre os produtos. As influenciadoras digitais também exercem um papel muito importante no aumento das vendas, divulgando os produtos nas redes sociais. Todas as influenciadoras parceiras da Ocean Drop são qualificadas no sentido de avaliar se sua imagem é sinérgica aos valores e ao público-alvo da empresa.

Outra estratégia fundamental para o crescimento da empresa é o marketing de conteúdo. Como não existem empresas especialistas em alimentação com microalgas no Brasil e as pessoas não conhecem esses produtos, a Ocean Drop entende que é fundamental gerar conteúdo próprio, de qualidade e revisado por nutricionistas para promover um melhor entendimento sobre as microalgas, tanto para os revendedores como para os consumidores. Para isso, a empresa mantém um blog, com atualização semanal, que apresenta tanto conteúdo de topo, instruindo as pessoas a como se alimentar melhor fora de casa, como de base, com os benefícios específicos da Spirulina e Chlorella.

\section{As decisões para o futuro}

Passadas duas semanas os quatro sócios se reuniriam novamente para a reunião na qual tomariam decisões importantes sobre o rumo dos negócios.

Os resultados conquistados até ali eram excelentes, mas diversas questões careciam de análise e decisões estratégicas para que a empresa continuasse a aumentar o volume de vendas e escalar nos dois canais, sem perder rentabilidade. Mas como fazer isso?

Tinha algo que fazia Leandro refletir muito:

"Sem dúvidas temos decisões importantes a tomar. Mas tem outra coisa me fazendo pensar muito! Não quero parecer ingrato com o que conquistamos até aqui, alcançamos resultados que surpreenderam a todos. Mas, eu ainda acredito no sonho da Brastax! Estudamos muito para atuar na nossa área e hoje, trabalhamos como gestores e não como oceanógrafos. Será que a nossa ideia é tão 'maluca'assim? Acho que ainda vale a pena investir tempo e dinheiro na ideia que originou tudo isso!" 
A Brastax permanece viva nos ideais dos quatro jovens empreendedores. Mas será que há saída para uma ideia refutada tantas vezes pelo mercado? Não seria melhor aproveitar a "onda" da Ocean Drop para rentabilizar? De fato, essa seria uma reunião com muitas decisões a serem tomadas.

\section{Referências das Fontes de Dados do Caso}

Federação das Indústrias do Estado de Santa Catarina. (2015). Santa Catarina em dados/ unidade de política econômica e industrial. Florianópolis: Autor.

Santander. (2012). Projeto da oportunidade empreendedora - Roteiro e Check-list final. Recuperado de https://www.santander.com.br/document/wps/Roteiro_Plano_Empreendedor_PSU_2013.pdf

Santander. (2015). Abertas as inscrições para a $11^{a}$ edição dos Prêmios Santander. Recuperado de https://sustentabilidade.santander.com.br/pt/Espaco-de-

Praticas/Paginas/Abertasasinscricoesparaa11edicaodosPremiosSantander.aspx

União Brasileira de Avicultura (2012). Relatório Anual 2012. - São Paulo: UBABEF. 


\title{
Notas de Ensino
}

\section{Resumo}

O presente caso de ensino propõe aos alunos, a necessidade de analisar estrategicamente o modelo de negócio adotado pela Ocean Drop - primeira empresa brasileira especialista em nutrição com microalgas, de forma que a mesma possa continuar aumentando a sua escalabilidade sem afetar a rentabilidade. O caso também provoca uma reflexão sobre a adequação do plano de negócio em estágios iniciais da empresa e a utilização do modelo de negócio Canvas, como alternativa ao planejamento formal e sistemático em negócios inovadores. Este caso pode ser utilizado em cursos de pós-graduação ou MBA's, em disciplinas de Empreendedorismo, Inovação ou Gestão Estratégica. As situações relatadas neste caso são baseadas em uma estória real e o nome da empresa e dos empreendedores foram mantidos. As notas de ensino trazem sugestões de questões a serem discutidas em sala de aula, além de uma proposta de dinâmica para utilização do caso que possibilita relacionar os fatos com a literatura sobre construção e avaliação do modelo de negócio Canvas.

Palavras-chave: plano de negócio; modelo de negócio; caso de ensino.

\begin{abstract}
The present case of teaching proposes to students the need to strategically analyze the business model adopted by Ocean Drop - the first Brazilian company specialized in nutrition with microalgae, so that it can continue to increase its scalability without affecting profitability. The case also provokes a reflection on the adequacy of the business plan in the early stages of the company and the use of the Canvas business model as an alternative to formal and systematic planning in innovative business. This case can be used in postgraduate courses or MBA's, in subjects of Entrepreneurship, Innovation or Strategic Management. The situations reported in this case are based on a real story and the company name and characters have been retained. The teaching notes bring suggestions of issues to be discussed in the classroom, as well as a dynamic proposal for use of the case that makes it possible to relate the facts to the literature on the preparation of business plans and creation and evaluation of the Business Model Canvas.
\end{abstract}

Keywords: business plan; business model canvas; teaching case.

JEL Code: A2, M1, O21.

\section{Objetivos educacionais e utilização recomendada do caso}

Com base no relato da trajetória da empresa apresentada no caso de ensino, o mesmo pode proporcionar os seguintes objetivos de aprendizagem:

1. Discutir o processo de elaboração de um plano de negócio;

2. Analisar a utilidade do plano de negócio em estágios iniciais de empresas inovadoras;

3. Avaliar um modelo de negócio, sugerindo ações para o aprimoramento do modelo.

Sugere-se a utilização deste caso em disciplinas de Empreendedorismo, Inovação ou Gestão Estratégica de cursos de pós-graduação ou $M B A$ 's para abordagem dos seguintes temas: elaboração do plano de negócio, suas principais dificuldades e procedimentos importantes na elaboração do plano, construção e análise do modelo de negócio Canvas e discussão sobre a utilidade do plano de negócio tradicional em estágios iniciais de uma empresa.

Como questão principal, o caso instiga a tomada de decisão sobre os ajustes necessários no modelo de negócio para a empresa Ocean Drop aumentar a sua escalabilidade sem perder em rentabilidade além de quais alterações precisariam ser realizadas no modelo de negócio para que a ideia original (Brastax), refutada pelo mercado, pudesse ser validada junto ao mercado-alvo e implementada. 
Embora este não seja o seu foco principal, por tratar de uma empresa criada por estudantes universitários, que conquistou diversos prêmios e passou pelos processos de incubação e aceleração, caso seja foco da disciplina, o caso pode ser utilizado para provocar discussões acerca da importância do Ecossistema Empreendedor para o desenvolvimento de negócios de alto impacto.

Quanto a sua aplicação, sugere-se que o caso seja lido previamente pelos alunos. A socialização do caso pode ser iniciada por meio de uma discussão para atender aos dois primeiros objetivos educacionais, estimulando os alunos a refletirem e dialogarem sobre as dificuldades encontradas na fase de elaboração de um plano de negócio e os principais cuidados a serem observados nesse momento, além de refletir criticamente sobre a utilização do plano de negócio em empresas inovadoras.

Após essa etapa inicial, os alunos podem ser divididos em grupos com o intuito de elaborarem o modelo de negócio Canvas da Ocean Drop, avaliando o modelo atual com base em critérios com os quais já tenham sido familiarizados previamente (Ver análise do caso e conexão com a literatura).

No tocante à questão-chave do caso, os grupos podem apontar quais mudanças são necessárias para que a Ocean Drop aumente a sua escalabilidade, sem perder em rentabilidade. Também sugere-se que, ao final, seja fomentada uma discussão sobre as falhas na construção do plano de negócio e posteriormente, no teste de seu modelo junto ao mercado, que inviabilizaram a continuidade da Brastax e quais ajustes seriam necessários no modelo, caso os empreendedores desejassem retomar as atividades da empresa.

O presente caso de ensino, contém níveis de dificuldade, 3 e 2, conforme a escala de Leenders e Erskine (1989), na qual 1 (apresentação) representa um nível de complexidade fácil, 2 (conceitual) regular e 3 (analítica) difícil. A Tabela 1 apresenta cada objetivo educacional associado ao seu nível de complexidade, bem como uma estimativa do tempo sugerido para cada etapa da aula de aplicação do caso.

Tabela 1

Sugestão de Plano de Aula e Classificação dos Objetivos em Níveis de Dificuldade

\begin{tabular}{|c|c|c|c|}
\hline Etapa da aula & $\begin{array}{l}\text { Nível de } \\
\text { Complexidade }\end{array}$ & Objetivo Educacional & $\begin{array}{l}\text { Tempo } \\
\text { sugerido }\end{array}$ \\
\hline $\begin{array}{l}\text { Identificar as principais dificuldades e } \\
\text { falhas e os principais pontos fortes na } \\
\text { elaboração do plano de negócio da Brastax }\end{array}$ & 2 - Conceitual & $\begin{array}{l}\text { Discutir o processo de elaboração } \\
\text { de um plano de negócio }\end{array}$ & 30 minutos \\
\hline $\begin{array}{l}\text { Estimular os alunos a refletirem sobre a } \\
\text { utilização do plano de negócio tradicional } \\
\text { em empresas inovadoras }\end{array}$ & 2 - Conceitual & $\begin{array}{l}\text { Analisar a utilidade do plano de } \\
\text { negócio em estágios iniciais de } \\
\text { empresas inovadoras }\end{array}$ & \\
\hline $\begin{array}{l}\text { Dividir os alunos em grupos para que } \\
\text { elaborarem o modelo de negócio Canvas } \\
\text { da Ocean Drop, avaliando o modelo atual }\end{array}$ & 2-Conceitual & $\begin{array}{l}\text { Avaliar um modelo de negócio, } \\
\text { sugerindo ações para o } \\
\text { aprimoramento do modelo }\end{array}$ & 60 minutos \\
\hline $\begin{array}{l}\text { Solicitar aos grupos que avaliem quais as } \\
\text { mudanças necessárias para que a empresa } \\
\text { aumente a sua escalabilidade, sem perder } \\
\text { em rentabilidade }\end{array}$ & 3 - Analítica & $\begin{array}{l}\text { Avaliar um modelo de negócio, } \\
\text { sugerindo ações para o } \\
\text { aprimoramento do modelo }\end{array}$ & 60 minutos \\
\hline $\begin{array}{l}\text { Promover uma discussão sobre os motivos } \\
\text { que inviabilizaram a continuidade da } \\
\text { Brastax e quais ajustes seriam necessários } \\
\text { no modelo de negócio, caso os } \\
\text { empreendedores desejem retomar as } \\
\text { atividades da empresa }\end{array}$ & 3 - Analítica & $\begin{array}{l}\text { Avaliar um modelo de negócio, } \\
\text { sugerindo ações para o } \\
\text { aprimoramento do modelo }\end{array}$ & 30 minutos \\
\hline
\end{tabular}

Nota. Fonte: Elaborado com base em Leenders, M. R., \& Erskine, J. A. (1989). Case research: The case writing process (3rd ed., p. 120). Ontario: The University of Western Ontario. 
O planejamento acima foi elaborado com base em uma aula de três horas. No caso da utilização do caso em aulas reduzidas, sugere-se a aplicação das três primeiras etapas (até a construção do modelo de negócios) em um primeiro encontro e as duas últimas etapas (avaliação dos modelos de negócios) em um encontro subsequente.

\section{Fontes de dados}

Utilizou-se fontes primárias de dados para a construção deste caso de ensino, por meio de entrevista com Lucas Marder, um dos sócios da empresa, e fontes secundárias tais como: o site da empresa, reportagens e divulgações dos produtos em mídias sociais e relatórios e documentos utilizados pelos empreendedores na elaboração do plano de negócio inicialmente elaborado. Os nomes dos personagens foram alterados para preservar a identidade dos sócios da empresa.

\section{Questões para discussão}

De maneira a fomentar a discussão do caso, sugerem-se algumas questões:

1. Quais os principais acertos e erros dos empreendedores na elaboração do plano de negócio da Brastax?

2. Quais as dificuldades em elaborar um plano de negócio para uma empresa inovadora? Que medidas os empreendedores poderiam ter tomado ao invés de elaborar o plano de negócio de forma imediata?

3. Quais os pontos fortes e fracos, as oportunidades e ameaças do modelo de negócio atual da Ocean Drop e quais decisões ou mudanças precisam ser tomadas para que a Ocean Drop aumente a sua escalabilidade sem afetar a rentabilidade?

4. Que mudanças seriam necessárias no modelo de negócio da Brastax, caso os empreendedores decidissem retomar as atividades da empresa?

\section{Análise do caso e conexão com a literatura} propostas.

Nessa seção são apresentados os argumentos teóricos que possibilitam a solução das questões

\section{Plano de negócio}

O Plano de Negócio é uma ferramenta fundamental para o empreendedor planejar e traçar estratégias para seus empreendimentos. No Brasil esta ferramenta ganhou notoriedade no final da década de 90, motivada pelo crescimento do empreendedorismo no país (Dornelas, 2016). No entanto, ressaltase que, o plano de negócio não é uma ferramenta utilizada apenas para se iniciar um novo negócio, ele pode ser utilizado "seja para ampliar uma linha de montagem, verificar a viabilidade de se atender um novo mercado, seja para averiguar a viabilidade de um novo negócio, entre tantas outras exigências que o demandem" (Cecconello \& Ajzental, 2008, p. 9). Além disso, possui um caráter dinâmico, devendo ser atualizado sempre que necessário (Dornelas, 2016).

Na visão de Borges (2014), o plano de negócio é utilizado para dar início a um novo empreendimento, e por meio de um documento se registram as estratégias necessárias. Autores como García, Bedoya e Ríos (2010), definem o plano de negócio como um documento, no qual é possível contemplar e avaliar aspectos técnicos, administrativos, comerciais, financeiros e legais para a viabilização de um negócio sustentável a longo prazo. Dornelas (2016, p. 94) também se refere ao plano de negócio como "um documento usado para descrever um empreendimento e o modelo de negócio que sustenta a empresa".

Dentre os benefícios que o plano de negócio traz para uma organização estão a possibilidade de reduzir custos e de analisar a viabilidade do negócio, nos aspectos relacionados a operação, técnicos e 
administrativos (Dolabela, 2008). Bernardi (2014, p. 10) concorda que o plano de negócio possibilita estudar a viabilidade do negócio, e acrescenta que o mesmo "conduz e obriga o empreendedor ou o empresário a concentrar-se na análise do ambiente de negócios, nos objetivos, nas estratégias, nas competências, na estrutura, na organização, nos investimentos e nos recursos necessários".

Outro aspecto importante do plano de negócio é que o mesmo auxilia na captação de recursos junto a investidores (Filion \& Dolabela, 2000), ou seja, o plano de negócio se constitui em "uma das primeiras frentes de ação no processo de captação de recursos financeiros (Santiago, 2011, p. 57).

Com relação a forma de realizar um plano de negócio, diferentes modelos podem ser encontrados na literatura (Brandão, 2013; Dolabela, 2008; Dornelas 2016; Gauthier \& Macedo, 2007; Williams, 2002). Alguns deles mais voltados para empresas de inovação, tecnologia e outros para indústria.

Neste estudo, apresenta-se de forma resumida as etapas do plano de negócio de Dornelas (2016), pelo fato deste autor ser referência no tema, mas destaca-se que na obra do referido autor é possível evidenciar de forma pormenorizada a descrição de cada uma das etapas do plano de negócio que seguem:

Capa: traz a identificação da empresa e informações sobre a elaboração do plano de negócio, como nome dos elaboradores, data de criação e número da revisão;

Sumário: apresenta as seções que compõe o plano com suas respectivas páginas;

Sumário executivo: sintetiza para o leitor o que será abordado ao longo do plano;

Descrição da empresa: apresenta a empresa, sua história e seu contexto atual;

Produtos e serviços: descreve quais os produtos e serviços a empresa oferece;

- Mercado e competidores: constitui uma das partes mais importante do plano e mais complexa de se realizar, pois definirá como a empresa irá atingir seu mercado consumidor;

- Marketing e vendas: informa quais as estratégias de marketing será utilizada pela empresa para atingir seus objetivos.

- Análise estratégica: verifica e analisa quais as melhores alternativas para se alcançar os objetivos e metas traçadas.

- Plano financeiro: apresenta em números tudo que foi descrito e definido nas etapas anteriores.

Anexos: traz informações importantes para um melhor entendimento do plano de negócio.

Quanto as dificuldades ao se elaborar um plano de negócio, Dornelas (2016), destaca que muitos empreendedores consideram a etapa do plano financeiro como a mais complexa, visto a dificuldade de se reproduzir em números o que foi apresentado nas etapas anteriores do plano. Frente a esta dificuldade, Dornelas (2016), acrescenta que a prática na realização do plano, assim como a clareza dos objetivos do negócio, ajuda a minimizar esta dificuldade, no entanto, recomenda a busca de um profissional da área contábil e financeira para auxiliar o empreendedor nesta etapa.

Ainda no que diz respeito às dificuldades em sua elaboração, o principal problema de um plano de negócio, segundo Blank (2013) é ser um documento estático, que expressa a dimensão da oportunidade, indicando a solução que o novo empreendimento trará, projetando receitas, lucros e fluxo de caixa para períodos seguintes. O autor alega que, na elaboração de um plano de negócio, parte-se da premissa que é possível responder às interrogações de um novo empreendimento mesmo antes de desenvolver um produto e testar a ideia junto a possíveis clientes.

Antes de concretizar a ideia Maximiano (2011), alerta para a necessidade de se realizar uma avaliação do plano de negócio construído. Para isto, o autor sugere conforme Tabela 2, algumas questões que empreendedor precisa responder e posteriormente contemplar estas respostas em seu plano de negócio. 
Tabela 2

\section{Estudo da Viabilidade de um Negócio}

\begin{tabular}{ll}
\hline Aspectos a contemplar: & O que analisar: \\
\hline Demanda para produtos e serviços. & Mercado potencial, localização dos consumidores e volume de vendas. \\
\hline Concorrência & $\begin{array}{l}\text { Pontos fortes e pontos fracos em termos de localização, vantagem } \\
\text { competitiva, número de concorrentes e maneira de dominá-la. }\end{array}$ \\
\hline $\begin{array}{l}\text { Requisitos de operação para } \\
\text { produtos e serviços }\end{array}$ & $\begin{array}{l}\text { Estrutura necessária em termos de máquinas, instalações, recursos } \\
\text { humanos e componentes, para se garantir a fabricação do produto ou } \\
\text { realização de um serviço. }\end{array}$ \\
\hline $\begin{array}{l}\text { Fornecedores } \\
\text { Pesquisa e Desenvolvimento }\end{array}$ & $\begin{array}{l}\text { Oxistência de fornecedores diversos conforme a necessidade do negócio. } \\
\text { serviço, qual a estrutura e recursos necessários para possibilitar sua } \\
\text { pesquisa e desenvolvimento. }\end{array}$ \\
\hline $\begin{array}{l}\text { Requisitos legais } \\
\text { funcionamento do negócio }\end{array}$ & para \\
& $\begin{array}{l}\text { Impactos sociais, ambientais e aspectos legais para funcionamento do } \\
\text { negócio em um determinado local. Tipo de documentação necessária e } \\
\text { onde ter acesso a mesma. }\end{array}$ \\
\hline Recursos financeiros necessários & $\begin{array}{l}\text { Todos recursos financeiros necessários para atender a operação, os } \\
\text { aspectos técnicos e legais comparado com os recursos que o empreendedor } \\
\text { dispõe. } \\
\text { Caso, os recursos do empreendedor não sejam suficientes verificar onde } \\
\text { captar e como. }\end{array}$ \\
\hline
\end{tabular}

Nota. Fonte: Elaborado pelos autores com base em Maximiano, A. C. A. (2011). Administração para empreendedores. São Paulo: Person Prentice Hall.

\section{O modelo de negócios canvas}

Para Blank (2013), a forma tradicional de planejamento, com base no plano de negócio, parte da premissa de que é possível responder a maior parte das interrogações de um empreendimento já na fase de concepção da ideia, antes mesmo de levantar o capital necessário e contatar os clientes. $\mathrm{O}$ autor defende, porém, que antes de escrever um plano de negócio, empreendedores a frente de startups devem preocupar-se em criar um modelo de negócio através da metodologia Canvas. Esse método foi desenvolvido por Osterwalder e Pigneur (2011) e consiste em um diagrama que permite representar, visualizar, avaliar e alterar as decisões-chave de uma empresa.

"Um modelo de negócios descreve a lógica de criação, entrega e captura de valor de uma organização" (Osterwalder \& Pigneur, 2011, p. 14). Segundo os autores, o modelo de negócio Canvas é formado por nove componentes:

- Segmento de clientes: qual (ou quais) os segmentos de clientes que a empresa busca servir;

- Proposta de valor: de que maneira a empresa resolve os problemas do(s) segmento(s) de clientes ou satisfaz as suas necessidades;

Canais: como a(s) proposta(s) de valor é(são) levada(s) aos clientes, em termos de canais de distribuição e comunicação;

Relacionamento com os clientes: como a relação com o(s) segmento(s) de clientes é estabelecida e mantida;

- Fontes de receita: como as propostas oferecidas ao(s) segmento(s) de clientes resultam em receita para a empresa; 
Recursos principais: quais os ativos necessários para entregar a(s) proposta(s) de valor aos clientes;

Atividades-chave: quais atividades são essenciais p a entrega de valor ao(s) segmento(s) de clientes;

Parcerias principais: quais atividades são terceirizadas no processo;

Estrutura de custos: quais custos envolvidos na operação do modelo de negócios.

Para Osterwalder e Pigneur (2011), o diagrama do modelo de negócio deve ser impresso em um quadro pôster, fixado na parede e a partir de então os quadrantes vão sendo preenchidos com post-its, embora diversas ferramentas online e colaborativas permitem a criação do quadro.

Essa primeira versão do Canvas, porém, é composta apenas por hipóteses, que precisam ser comprovadas. Nenhum empreendedor, está totalmente ciente das necessidades reais dos clientes e, por mais que tenha desenvolvido uma série de pesquisas, o que se tem inicialmente são apenas possibilidades que precisam ser validadas (ou pivotadas) pelo mercado (Blank, 2013). Cada hipótese pivotada é revista no modelo de negócio, que vai sendo ajustado conforme as iterações, ou idas e vindas do mercado. $\mathrm{O}$ termo pivotar, no contexto das startups significa mudar a estratégia do serviço ou produto, é o momento em que o empresário precisa decidir se persevera ou pivota com a estratégia original (Ries, 2014).

Nessa lógica, a opinião do cliente deve ser ouvida desde cedo, sem que se leve adiante as ideias até que se tenha clareza do que os clientes querem. Esse processo é denominado desenvolvimento com clientes e tem como resultado a criação de um Minimum Viable Product (Produto Mínimo Viável) algo que se assemelha a um produto/serviço, que emprega o menor número de recursos possível, mas o qual o cliente valoriza (Blank, 2013). Esse processo, normalmente, é resultado de várias iterações, tentativa e erro, e protótipos testados junto a muitos clientes. Para Dimov (2011), a oportunidade visualizada inicialmente vai evoluindo por meio de um ciclo de ideias e ações cada vez que o empreendedor vai ao mercado e incorpora o novo conhecimento proporcionado pela iteração, modificando o seu modelo.

Sarasvathy (2001) propõe dois diferentes modos para a exploração de uma oportunidade de negócio. O primeiro deles, denominado causation acontece quando o empreendedor possui um objetivo em mente e age para implementar suas ideias, numa lógica causal. Nesta perspectiva, o empreendedor planeja o conjunto de ações necessárias para chegar a um resultado final e a oportunidade surge da análise de informações as quais o empreendedor tem acesso. No segundo processo, denominado pela autora de effectuation, as oportunidades são criadas por meio da interação do empreendedor com o ambiente. Não há um objetivo final em mente e sim um aproveitamento das contingências, experiências e parcerias para desenvolver efeitos possíveis a partir dos meios disponíveis.

\section{Avaliação do modelo de negócio}

A avaliação de um modelo de negócio deve levar em consideração tanto a consistência entre os nove componentes, como os detalhes de cada um dos quadrantes. Uma maneira simples e eficiente para realizar essa tarefa é combinando a clássica Análise SWOT (Forças, Fraquezas, Oportunidades e Ameaças) ao quadro do modelo de negócio. Para realizar essa análise, deve-se fazer duas perguntas amplas: quais as principais forças e fraquezas da empresa? E quais oportunidades a empresa tem a explorar e quais ameaças enfrenta no ambiente de negócios? Essas questões devem ser feitas a cada um dos nove quadrantes e ao modelo como um todo, fornecendo uma boa base para discussões mais aprofundadas sobre a necessidade de inovar no modelo de negócio (Osterwalder \& Pigneur, 2011).

Além desse método de avaliação, Osterwalder e Pigneur (2011) apresentam um questionário que pode ser utilizado para avaliar cada um dos componentes do modelo de negócio em termos de forças, fraquezas, oportunidades e ameaças. Embora não seja possível apresentá-lo neste documento em função da extensão, esse procedimento mais sistemático pode ser empregado para análises mais consistentes de um modelo de negócio. A partir de qualquer um destes dois métodos de avaliação, é possível obter uma visão clara dos ajustes necessários em um modelo de negócio.

\section{Discussão}


Neste tópico, são apresentadas as possíveis respostas aos questionamentos sugeridos, com base na revisão de literatura apresentada.

\section{Quais os principais acertos e erros dos empreendedores na elaboração do plano de negócio da Brastax?}

Como acertos pode-se destacar que os empreendedores foram extremamente dedicados na busca de informações para a construção de um plano consistente e que despertasse a atenção dos avaliadores do concurso, o que, em muitos pontos superou a falta de formação específica da equipe para a elaboração do documento. A partir da estrutura fornecida no regulamento do concurso, os empreendedores pesquisaram exaustivamente a respeito, de maneira a superar o obstáculo da falta de conhecimentos.

Neste sentido, a forma como os números do mercado, a caracterização do problema e a proposta técnica extremamente inovadora, aliada a um momento oportuno, no qual o país vivia uma escassez de água grave, contribuíram para a conquista de prêmios. O plano de negócio, nesse momento, cumpriu um papel relevante para a empresa, no sentido de captar recursos e investimentos (Filion \& Dolabela, 2000; Santiago, 2011).

O estudo do potencial de mercado foi um dos pontos que mais chamou a atenção no documento. A utilização de fontes de dados secundárias que indicavam o tamanho do mercado foi uma escolha feliz, mas que de certa forma, pode ter ocultado a necessidade de consulta junto ao mercado-alvo se a ideia era, de fato, viável do ponto de vista dos compradores. Neste sentido, os empreendedores pecaram por deixar de verificar junto ao mercado, o potencial de vendas da solução criada (Maximiano, 2011).

Nesta perspectiva, Blank (2013) critica o processo de elaboração do plano de negócio que, por vezes, aborda diversos pontos antes de desenvolver e testar a ideia junto ao mercado-alvo. Em outras palavras, o plano de negócio vendia bem uma ideia, mas que o mercado mostrou, mais tarde, não ter interesse em comprar.

Outra dificuldade dos empreendedores no momento de elaboração do plano, foram as projeções financeiras (Dornelas, 2016). A própria indefinição de como gerar receita, denota que as projeções realizadas não eram suficientemente refinadas, o que se revelou nos momentos seguintes.

\section{Quais as dificuldades em elaborar um plano de negócio para uma empresa inovadora? Que medidas os empreendedores poderiam ter tomado ao invés de elaborar o plano de negócio de forma imediata?}

O caso demonstra como a falta da validação de uma ideia junto ao mercado pode comprometer a sua eficácia. Na fase da Brastax, inicialmente, o que se percebe é um modelo de exploração de oportunidades denominado por Sarasvathy (2001) como causation. Os empreendedores tinham uma ideia em mente e elaboraram um plano de negócio para criação de uma empresa para explorar essa oportunidade. Porém, o contato com o mercado foi subestimado. Percebe-se que, na elaboração do plano, os empreendedores recorreram a diversas fontes secundárias para levantar o potencial do mercado que, parecia ter capacidade de absorver a tecnologia desenvolvida. Nesse sentido, o plano de negócio foi extremamente útil para participar dos prêmios, captar recursos e poder investir na ideia.

Contudo, considerando uma lógica de effectuation os empreendedores poderiam ter interagido com o ambiente de forma mais efetiva e rápida. $\mathrm{O}$ planejamento meticuloso elaborado pelos empreendedores, ainda na fase da Brastax, mesmo feito com esmero, reconhecido e premiado diversas vezes, mostrou-se pouco ajustado às demandas do mercado. Testes de hipóteses nessa fase inicial, teriam demonstrado a necessidade de ajustes no modelo, afim de encontrar um produto mínimo viável aceito pelo mercado. Para Blank (2013), essa metodologia, chamada de lean startup, prioriza a experimentação em detrimento do planejamento minucioso e tem tornado menos arriscado o processo de abrir uma empresa. 
Além do desenvolvimento de um Minimum Viable Product, outro grande desafio à frente de uma startup, segundo Ries (2014), é torná-la a mais enxuta possível, economizando tempo e recursos, fazendo testes e ouvindo o cliente desde muito cedo para realizar ajustes necessários no modelo de negócios. Quanto maior for a velocidade e menores os custos de cada iteração maior as chances de sucesso da startup.

Não se trata de afirmar que o modelo de negócio é mais adequado que o plano de negócio. Ambos os documentos são importantes, todavia apropriados para momentos distintos. Na fase de concepção de ideia inovadora, na qual as dúvidas são maiores do que as certezas, o modelo de negócio torna-se mais viável. Com um modelo estruturado e testado, pode-se partir para a elaboração de um documento mais consistente como o plano de negócio (Blank, 2013).

\section{Quais os pontos fortes e fracos, as oportunidades e ameaças do modelo de negócios atual da Ocean Drop e quais decisões ou mudanças precisam ser tomadas para que a Ocean Drop aumente a sua escalabilidade sem afetar a rentabilidade?}

No caso da Ocean Drop, as principais forças do modelo de negócio estão em definir claramente segmentos de clientes a serem atendidos e uma proposta de valor adequada a cada um desses segmentos. Outro ponto forte são as estratégias de comunicação da empresa com o público-alvo (relacionamento com o cliente). Os principais pontos fracos do modelo estão no fato de a empresa terceirizar toda a sua produção, o que reduz significativamente a rentabilidade. Porém, dado o investimento necessário para que a empresa produzisse a sua própria matéria-prima, esta foi a alternativa mais viável. Embora os produtos da Ocean Drop apresentem melhor custo-benefício que os concorrentes, a compra inicial acaba tornando-se mais onerosa pelo fato de as embalagens serem suficientes para dois meses de consumo, enquanto concorrentes possuem embalagens reduzidas. $\mathrm{O}$ índice de recompra apresentado até o momento também é um ponto que precisa ser melhor trabalhado. A principal ameaça consiste na falta de percepção de resultados por parte dos consumidores. A empresa necessita investir em ferramentas que potencializem os resultados percebidos pelos usuários de Spirulina e Chlorella. Em termos de oportunidades, a empresa possui possibilidades de expandir suas vendas, aumentando as linhas de produtos, investindo em novos canais e estimulando a recompra por parte dos clientes já cadastrados.

\section{Que mudanças seriam necessárias no modelo de negócio da Brastax caso os empreendedores decidissem retomar as atividades da empresa?}

A principal medida para viabilizar a atuação da Brastax consiste na criação de um Minimum Viable Product desenvolvido por meio de iterações com o mercado (Blank, 2013). A empresa necessitaria definir claramente quem é o seu segmento de clientes-alvo e qual proposta de valor oferecer a esse segmento (Osterwalder \& Pigneur, 2011), interagindo com o ambiente de forma a coletar informações e reformular as suas estratégias, pivotando as hipóteses que se mostrarem equivocadas (Ries, 2014). Percebendo que no mercado tradicional não houve aceitação, talvez um direcionamento para mercados diferenciados, como a produção de frangos e outras aves em modo orgânico, ou produtores que objetivem se diferenciar do mercado, agregando valor a marca por meio da sustentabilidade, poderiam ser caminhos pensados pela empresa. Nesse sentido, tanto segmento de clientes quanto proposta de valor precisariam ser revistos. É importante também definir, por meio de iterações junto ao mercado uma forma ideal de gerar receitas para a empresa, o que foi uma grande dúvida para os empreendedores. Nesse sentido, há possibilidades de a monetização ocorrer por quilo de alga produzida, por litro de água tratada, pela venda de uma planta com capacidade pré-determinada e operação por parte da empresa compradora, entre outros modelos.

A empresa poderia realizar uma parceria com algum de seus possíveis clientes para testar na prática a viabilidade da solução proposta, tendo um protótipo testado para convencer o mercado da eficácia da tecnologia desenvolvida, aumentando a aceitação do mercado. No caso de não conseguir parcerias com empresas privadas, haveria ainda a possibilidade de contatar órgãos públicos como empresas de pesquisa agropecuária e institutos federais e universidades que possuam criação de animais. 


\section{Referências}

Bernardi, L. A. (2014). Manual de plano de negócio: fundamentos, processos e estruturação. São Paulo: Atlas.

Blank, S. (2013). Por que o movimento lean startup muda tudo. São Paulo: Harvard Business Review Brasil.

Borges, C. (2014). Empreendedorismo sustentável e o processo de criação de empresas. In C. Borges (Org.), Empreendedorismo sustentável (pp. 1-12). São Paulo: Saraiva.

Brandão, F. G. (2013). Plano de negócios: Material de apoio para a fase de pré-incubação de empresas. Porto Alegre: UERGS.

Cecconello, A. R., \& Ajzental, A. (2008). A construção do plano de negócio: percurso metodológico para: caracterização da oportunidade, estruturação do projeto conceptual, compreensão do contexto, definição do negócio, desenvolvimento da estratégia, dimensionamento das operações, projeção de resultados, análise de viabilidade. São Paulo: Saraiva.

Dimov, D. (2011). Grappling with the unbearable elusiveness of entrepreneurial opportunities. Entrepreneurship Theory and Practice, 35(1) 57-81. https://doi.org/10.1111/j.15406520.2010.00423.x

Dolabela, F. (2008). O segredo de Luiza. Rio de Janeiro: Sextante.

Dornelas, J. C. A. (2016). Empreendedorismo: Transformando ideias em negócio. São Paulo: Atlas.

Filion, L. J., \& Dolabela, F. (2000). Boa ideia! E agora? Plano de negócio, o caminho seguro para criar e gerenciar sua empresa. São Paulo: Editora de Cultura.

García, J. A. C., Bedoya, L. J. R., \& Ríos, C. E. C. (2010). Importance of financial planning in business plan elaboration and its impact on enterprise development. Revista Facultad de Ciencias Económicas: Investigación y Reflexión, 18(1), 179-194.

Gauthier, F. Á. O., \& Macedo, M. (2007). Criando e organizando uma empresa de tecnologia da informação. Florianópolis: Ed. do Autor.

Leenders, M. R., \& Erskine, J. A. (1989). Case research: The case writing process (3rd ed.). Ontario: The University of Western Ontario.

Maximiano, A. C. A. (2011). Administração para empreendedores. São Paulo: Person Prentice Hall.

Osterwalder, A., \& Pigneur, Y. (2011). Business model generation: Inovação em modelos de negócios. Rio de Janeiro: Alta Books.

Ries, E. (2014). A startup enxuta. São Paulo: Leya.

Santiago, R. A. (2011). Captação de recursos financeiros privados por empresas nascentes de base tecnológica: estudo de múltiplos casos de empresas mineiras e paulistas (Dissertação de mestrado) Universidade Federal de Minas Gerais, Belo Horizonte, BH, Brasil. Recuperado de http://www.bibliotecadigital.ufmg.br/dspace/handle/1843/BUOS-8MDG48

Sarasvathy, S. D. (2001). Causation and effectuation: Toward a theoretical shift from economic inevitability to entrepreneurial contingency. Academy of Management Review, 26(2), 243263. https://doi.org/10.5465/AMR.2001.4378020 
Williams, E. (2002). Plano de negócio: 25 princípios para um planejamento consistente (E. Rocha, Trad.). São Paulo: Publifolha.

\author{
Autores \\ Gustavo Behling \\ Rua João Coan, 400, 88161-064, Biguaçu, SC, Brasil \\ E-mail: behling@univali.br \\ Diulnéia Granja Pereira \\ Rua João Coan, 400, 88161-064, Biguaçu, SC, Brasil \\ E-mail: diulneia_diul@hotmail.com \\ Sidnei Vieira Marinho \\ Rua João Coan, 400, 88161-064, Biguaçu, SC, Brasil \\ E-mail: sidnei@univali.br
}

\title{
Contribuições
}

$1^{\circ}$ autor: planejamento, coleta de dados primários e redação do caso.

$2^{\circ}$ autor: planejamento e redação do caso.

$3^{\circ}$ autor: planejamento e redação do caso.

\section{Financiamento}

Os autores informaram que não há existência de apoio financeiro para a pesquisa neste artigo.

\section{Conflito de Interesses}

Os autores informaram que não existe conflito de interesses.

\section{Verificação de Plágio}

A RAC mantém a prática de submeter todos os documentos aprovados para publicação à verificação de plágio, mediante o emprego de ferramentas específicas, e.g.: iThenticate. 